\title{
Effect of Limestone Powder on Thaumasite Form of Sulfate Attack (TSA) of Cement-Based Materials
}

\author{
Yuxin Gao $\mathbb{D}^{1,2}$ Yaoling Luo $\mathbb{D},{ }^{1,2}$ Lili Jia $\mathbb{D},{ }^{2}$ Wen Yang $\mathbb{D}^{2}$, and Chong Wang $^{1}$ \\ ${ }^{1}$ College of Materials Science and Engineering, Chongqing University, Chongqing, 400045, China \\ ${ }^{2}$ China West Construction Academy of Building Materials, Chengdu 610015, China \\ Correspondence should be addressed to Yaoling Luo; cqulyl@qq.com
}

Received 28 May 2021; Accepted 29 July 2021; Published 6 August 2021

Academic Editor: Peerapong Jitsangiam

Copyright (c) 2021 Yuxin Gao et al. This is an open access article distributed under the Creative Commons Attribution License, which permits unrestricted use, distribution, and reproduction in any medium, provided the original work is properly cited.

Limestone powder can cause the thaumasite form of sulfate attack (TSA) of cement-based materials, but the relationship between the content of limestone powder and the degree of TSA is unclear. Hence, six different contents of limestone powder $(0 \%$, $5 \%$, $10 \%, 15 \%, 30 \%$, and $45 \%$ ) were used to study the effect of the limestone powder content on the TSA of cement-based materials according to appearance and Fourier transform infrared spectroscopy (FTIR), Raman spectroscopy, X-ray diffraction (XRD), and chemical analyses. The test results indicated that limestone powder could promote sulfate attack. The formation of ettringite and gypsum was accelerated when the content of the limestone powder was not more than $10 \%$. The degradation degree of the TSA was the most severe when the content of limestone powder was $30 \%$. A new product, hydrated calcium carboaluminate, was found when the content of the limestone powder was $45 \%$, and the degradation of the TSA was also delayed.

\section{Introduction}

In the natural environment, thaumasite is a rare six-sided crystalline mineral that mainly exists in metamorphic rocks and limestone $[1,2]$. Thaumasite consists of silicate, carbonate, sulfate, and water. The thaumasite formation (TF) was first reported by Erlin and Stark in 1965 and was found in sewers, cement grouting layers, and road holes [3]. The formation of thaumasite is a complex process in multifactorial environments that includes temperature, humidity, the type of sulfate, the concentration of sulfate, the $\mathrm{pH}$ of the environment, the type of cementitious material, and the type of aggregates. The typical degradation caused by the formation of large amounts of thaumasite leads to the transformation of cement-based materials into grey pulp that loses its cementitious properties, known as the thaumasite form of sulfate attack (TSA) [4-6]. The TSA was found in a 30-year highway bridge in Gloucestershire, England, in the 1990s [7]; hence, thaumasite expert groups were established by the UK government [8]. After that, the research on thaumasite began to appear more frequently, and the first international conference on TSA was held in the UK in July 2002 [9].
Carbonate is a necessary ingredient of thaumasite. Thaumasite is generated and TSA is present when carbonate or bicarbonate is available, as well as when there is adequate moisture and a low temperature. The sources of carbonate are generally divided into internal and external sources, which generally come from cement itself, concrete aggregates, and additives, while external sources come from groundwater and $\mathrm{CO}_{2}$ in the atmosphere [10]. A high content of limestone powder can greatly increase the risk of concrete corrosion from TSA [11-16], and carbonate and ettringite can obviously promote TSA [17]. At present, the limestone content of most cement is approximately $5 \%$. Cement is clearly classified according to the content of limestone in the cement when the content of the limestone in the cement exceeds 5\%. In Portland cement used throughout the world, the content of limestone is generally between $5 \%$ and $35 \%$, while the most widely used Portland cement currently contains between $5 \%$ and $20 \%$ limestone, as defined in the adopted European standard CEM II/A [18]. The main purpose of adding limestone to cement is to reduce the amount of clinker in the cement, which can greatly reduce the energy and carbon emissions. Although the heavy use of 
limestone reduces energy consumption, it also increases the risk of TSA in concrete, especially in large quantities [1-3].

The duration of TSA degradation is long, usually several years, which is not conducive to rapid development in the laboratory. Many studies by Luo et al. [19-21] and Zeng et al. [22] have indicated that an electrical field can accelerate the TSA of cement-based materials. Hence, the electrical field acceleration method can be utilized to study the effects of the limestone content on the TSA mechanism and process of cement-based materials within a short duration. The limestone powder will lead to TSA in sulfate attack environment, but the relationship between the content of limestone powder and the degree of TSA is unclear. Besides, the corrosion test is difficult to carry out in the laboratory due to the long time of TSA in the actual environment. Hence, the influence of six kinds of limestone powder content $(0 \%, 5 \%, 10 \%, 15 \%, 30 \%$, and $45 \%)$ on TSA of cement-based materials was studied by means of electric field acceleration method, and the influence degree and mechanism of limestone powder content on TSA were explored.

\section{Materials and Methods}

2.1. Preparation of the Basic Materials. The cement consists of $97 \%$ Portland cement clinker and 3\% gypsum, and its specific surface area is $320 \mathrm{~m}^{2} / \mathrm{kg}$. The limestone powder consists of more than $98 \% \mathrm{CaCO}_{3}$, and its specific surface area is $266 \mathrm{~m}^{2} / \mathrm{kg}$. The chemical components of the clinker, gypsum, and limestone powder are shown in Table 1.

2.2. Experimental Methods. The cement pastes were made with different limestone powder contents of $0 \%, 5 \%, 10 \%$, $15 \%, 30 \%$, and $45 \%$. The water/cementitious material ratio was 0.40 (shown in Table 2), and the size of the specimen was $40 \mathrm{~mm} \times 40 \mathrm{~mm} \times 40 \mathrm{~mm}$. After 24 hours of moulding, the specimen was cured in a mould for 30 days and then placed in a low temperature environment with a temperature of $5 \pm 2^{\circ} \mathrm{C}$. The electrical voltages were $30 \mathrm{~V}$, and the periods were $20 \mathrm{~s}$. The mould and schematic diagram for electrification are shown in Figure 1 . The cathode is a $\mathrm{Na}_{2} \mathrm{SO}_{4}$ solution, the anode is a $\mathrm{MgSO}_{4}$ solution, and the concentrations of $\mathrm{SO}_{4}{ }^{2-}$ are both $3.38 \mathrm{wt} \%$ [19-22].

The changes in the appearance of the specimen were observed, photographed, and recorded every 30 days, and the corrosion level was recorded according to Table 3 [20].

The microspecimens were created for XRD, FTIR, Raman, and chemical analyses. The specimens were sliced to the cathode surface and anode surface, and the thickness of the sliced specimen was $4 \mathrm{~mm}$ (shown in Figure 2).

The broken pieces were soaked and rinsed using anhydrous alcohol and dried at $50^{\circ} \mathrm{C}$ in the oven. The X-ray diffractometer was from Ricoh Company with D/MAX-IIIC and $\operatorname{CoK} \alpha$ radiation $(0.2 \AA)$. A Fourier transform infrared spectroscopy (FTIR) instrument with a resolution of $2.25 \mathrm{px}^{-1}$ was adopted. Raman spectroscopic measurements were carried out using a HORIBA Jobin Yvon S.A.S spectrometer (product model: LabRAM HR Evolution; spectral resolution: visible spectrum $\leq 0.65 \mathrm{~cm}^{-1}$; spectral region from $200 \mathrm{~nm}$ to $1050 \mathrm{~nm}$ ).

The chemical analysis included the $\mathrm{pH}$, content of $\mathrm{SO}_{3}$ and content of $\mathrm{CaO}$. The content of sulfate in the powder specimens was expressed by the content of $\mathrm{SO}_{3}$, which was based on the determination method of $\mathrm{SO}_{3}$ in the Chinese standard method (GB/T 176-2017) [23], barium sulfate gravimetric method (reference method), expressed by $\%$. The calcium content in the specimen was calculated by $\mathrm{CaO}$, and the test was conducted in accordance with the EDTA titration method (reference method), the determination method of $\mathrm{CaO}$ in the Chinese standard method (GB/T 1762017) [23], as \%. The $\mathrm{pH}$ value of the specimens was determined by solid solution extraction.

\section{Results and Discussion}

3.1. Appearance of the Specimens. The apparent failure degree of the specimens at 120 days of degradation and the appearance of the specimens at 120 days of degradation were observed and recorded, as shown in Figures 3 and 4 . The specimens were almost untouched by degradation within 120 days when the content of limestone was from $0 \%$ to $10 \%$. The specimens began to show significant degradation when the content of the limestone powder was more than $10 \%$, and the degradation degree was as follows: the content of $30 \%$ limestone powder $>$ the content of $45 \%$ limestone powder $>$ the content of $15 \%$ limestone powder. A small amount of grey pulp was found on the cathode edge of the $15 \%$ limestone powder specimen, the 30\% limestone powder specimen was almost completely argillaceous, grey pulp was found only on the surface of the cathode of the $45 \%$ limestone powder specimen, and the appearance of the limestone powder specimen with less than $15 \%$ limestone powder hardly changed within 120 days, as shown in Figure 4.

\subsection{Microstructure Analysis}

3.2.1. The FTIR and Raman Spectroscopy. The author's previous experiments [19-21] showed that TSA mainly occurs in the cathode region of the specimen; hence, the identification of thaumasite focuses on the cathode of samples. The microstructure specimens were obtained from the cathode surface of 6 groups and were tested by FTIR and Raman spectroscopy to identify the type of degradation products, as shown in Figure 5. The vibrational spectra and band assignment of thaumasite are shown in Table 4 [21]. The diffraction peak of thaumasite was the most significant when the content of limestone powder was $30 \%$, followed by the $45 \%$ content of limestone powder. There was no obvious diffraction peak of thaumasite when the content of limestone powder was less than $15 \%$. The degradation mechanism is herein analyzed by XRD and chemical analyses.

3.2.2. XRD Analysis. The XRD analysis of the 6 groups at 30 days is shown in Figure 6, in which specimens were cured for 30 days. The diffraction peak of ettringite is the highest when 
TABLE 1: Chemical components of the clinker, gypsum, and limestone powder (wt\%).

\begin{tabular}{|c|c|c|c|c|c|c|c|c|c|}
\hline Materials & $\mathrm{SiO}_{2}$ & $\mathrm{Fe}_{2} \mathrm{O}_{3}$ & $\mathrm{Al}_{2} \mathrm{O}_{3}$ & $\mathrm{CaO}$ & $\mathrm{MgO}$ & $\mathrm{SO}_{3}$ & $\mathrm{~K}_{2} \mathrm{O}$ & $\mathrm{Na}_{2} \mathrm{O}$ & LOI \\
\hline Clinker & 19.99 & 2.98 & 4.80 & 61.22 & 3.27 & 0.23 & 0.88 & 0.18 & 3.52 \\
\hline Gypsum & 4.47 & 0.36 & 0.99 & 34.05 & 1.84 & 40.61 & 0.23 & 0.08 & 16.87 \\
\hline Limestone powder & 0.23 & 0.21 & - & 55.46 & - & - & - & - & 41.75 \\
\hline
\end{tabular}

TABLE 2: Mixture proportions of the cement paste.

Cementitious materials

(wt\%) Water/cementitious materials ratio

Cement Limestone powder

\begin{tabular}{lcl}
\hline 100 & 0 & 0.40 \\
95 & 5 & 0.40 \\
90 & 10 & 0.40 \\
85 & 15 & 0.40 \\
70 & 30 & 0.40 \\
55 & 45 & 0.40 \\
\hline
\end{tabular}

the content of limestone powder is $5 \%$, and then with the increase in the content of limestone powder, the diffraction intensity of ettringite decreases gradually. The diffraction peaks of ettringite, calcium hydroxide, and other cement hydration products for the content of $45 \%$ limestone powder were very low. In addition, the higher the content of limestone powder, the lower the content of cement in the specimen, which will also lead to a decrease in the content of hydration products.

The XRD patterns of the cathode and anode surfaces of the 6 groups are shown in Figure 7. The above FTIR and Raman results showed that the specimens with $30 \%$ and $45 \%$ contents were thaumasite, and the remaining contents were not thaumasite. The XRD of the cathode surface shown in Figure 7 shows that only a small amount of ettringite was generated in the specimen containing $0 \%$ limestone powder after 120 days of degradation and that large amounts of ettringite and gypsum were generated in the specimen containing $5 \%$ to $15 \%$ limestone powder. In addition, calcium hydroxide was still present, indicating that the calcium hydroxide had not been consumed and the degradation degree was low. Large amounts of thaumasite and gypsum were produced when $30 \%$ limestone powder was added, while almost all of the calcium hydroxide was consumed. A small amount of thaumasite was produced from $45 \%$ limestone powder, and a significant presence of monocarboaluminate and tricarboaluminate was also found.
There were obvious diffraction peaks of ettringite and calcium hydroxide on the anode surface with 5\% and 10\% limestone powder, indicating that the degradation degree was low. The degradation products on the anode surface with 30\% limestone powder content were still mainly thaumasite and gypsum. Almost no degradation products were found on the anode surface with $45 \%$ limestone powder content. The diffraction peaks of the main phases on the anode surface of the specimen were calcium carbonate.

To study the role of the limestone powder in cementbased material TSA, the XRD of the cathode surface and anode surface of 6 groups of specimens were tested, as shown in the following figures. The XRD pattern for the $0 \%$ content of limestone powder within 120 days is shown in Figure 8. The main phases of the cathode surface and anode surface of the specimen were ettringite, calcium hydroxide, and calcium carbonate. The diffraction peak of the ettringite had the highest diffraction intensity for the $0 \%$ limestone powder content. After being exposed to the electric field, the diffraction peak of ettringite gradually disappeared, and ettringite gradually began to form after 90 days of degradation. In addition, it can be observed that the diffraction peak of gypsum was obviously found within 30 to 90 days of degradation, while no diffraction peak of gypsum was found at 0 and 120 days. Meanwhile, the diffraction intensity of the diffraction peak of the calcium hydroxide was first weakened and then enhanced from 0 to 90 days. In the early stages of degradation, calcium hydroxide was consumed in large quantities to form gypsum, while ettringite decomposed, which also produced gypsum (reaction 1). Ettringite decomposition is caused by magnesium ions and hydrogen ions electrolyzed by the anode entering the specimen and lowering the $\mathrm{pH}$ value inside the specimen. A large amount of sulfates concentrated at the cathode of the specimen and began to regenerate ettringite with the development of degradation. In addition, diffraction peaks of calcium carbonate were found in the XRD patterns, indicating that the specimens were carbonized.

$$
3 \mathrm{CaO} \cdot \mathrm{Al}_{2} \mathrm{O}_{3} \cdot 3 \mathrm{CaSO}_{4} \cdot 32 \mathrm{H}_{2} \mathrm{O}+4 \mathrm{SO}_{4}^{2-}+8 \mathrm{H}^{+} \longrightarrow 4 \mathrm{CaSO}_{4} \cdot 2 \mathrm{H}_{2} \mathrm{O}+2 \mathrm{Al}(\mathrm{OH})_{3}+12 \mathrm{H}_{2} \mathrm{O}
$$

Figure 9 shows the XRD pattern of the cathode surface and the anode surface of 5\% limestone powder within 120 days. Combined with the above data, according to the FTIR and Raman results, ettringite and gypsum were the main degradation products with $5 \%$ limestone powder, and no thaumasite was found in the specimens. The diffraction intensity of ettringite hardly changed, while that of gypsum gradually increased with the development of the degradation age, and the diffraction intensity of the calcium hydroxide diffraction peak did not decrease significantly. The results showed that the degradation degree was still very low at 120 days. Compared with that of the $0 \%$ content of limestone powder, the ettringite did not decompose in the $5 \%$ content of limestone powder, indicating that the existence of 

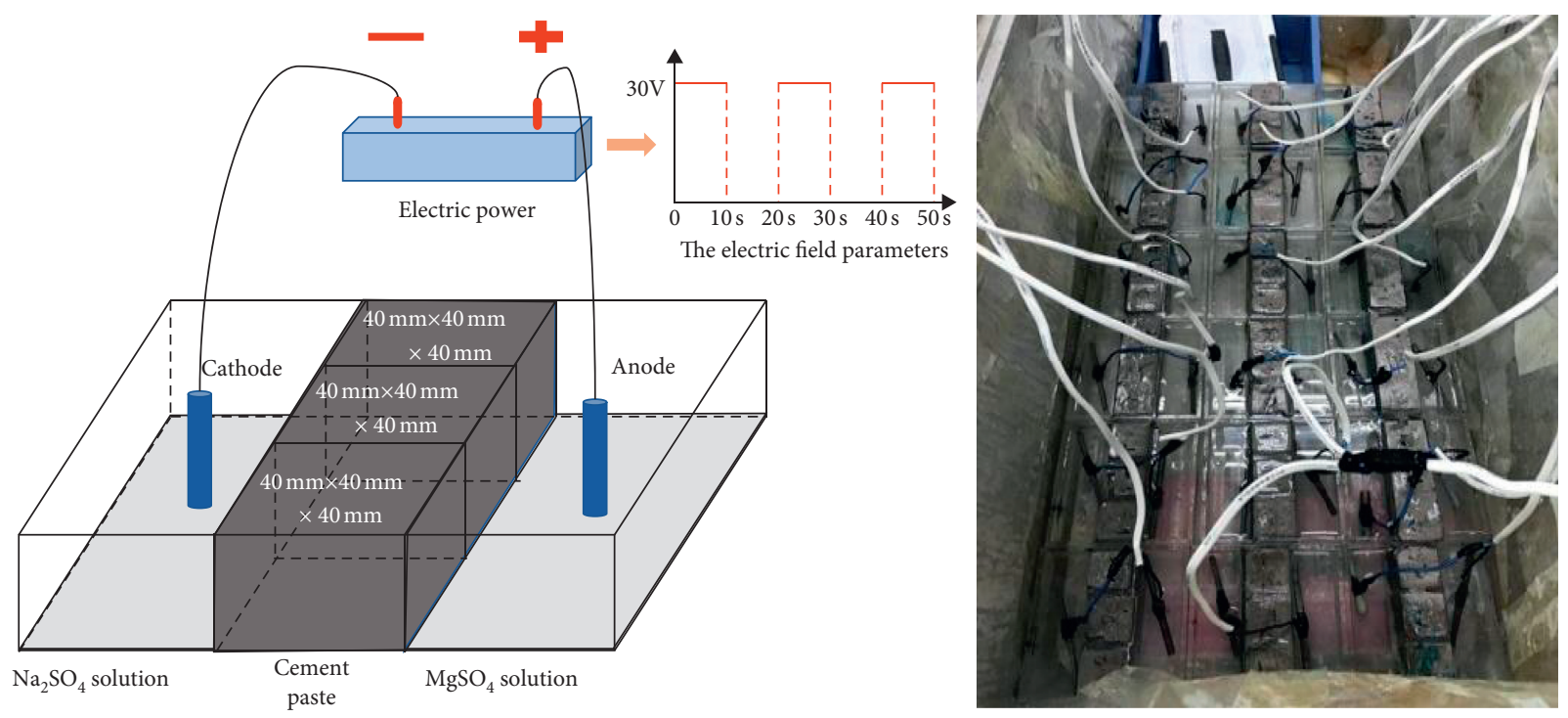

Figure 1: Mould and schematic diagram for electrification.

TABLE 3: Corrosion damage grade of TSA [20].

\begin{tabular}{lc}
\hline Damage grades & Corrosion features \\
\hline 1 & No visible deterioration \\
2 & Some deterioration at corners \\
3 & Deterioration at the corners and edges \\
4 & Deterioration at the corners and some \\
5 & cracking along the edges \\
6 & Cracking and expansion along the edges \\
7 & Serious cracking, expansion, or spalling \\
8 & Serious spalling or expansion of surfaces \\
9 & Grey pulp at the corners, edges, and surface \\
10 & Amount of grey pulp at the specimens \\
\hline
\end{tabular}

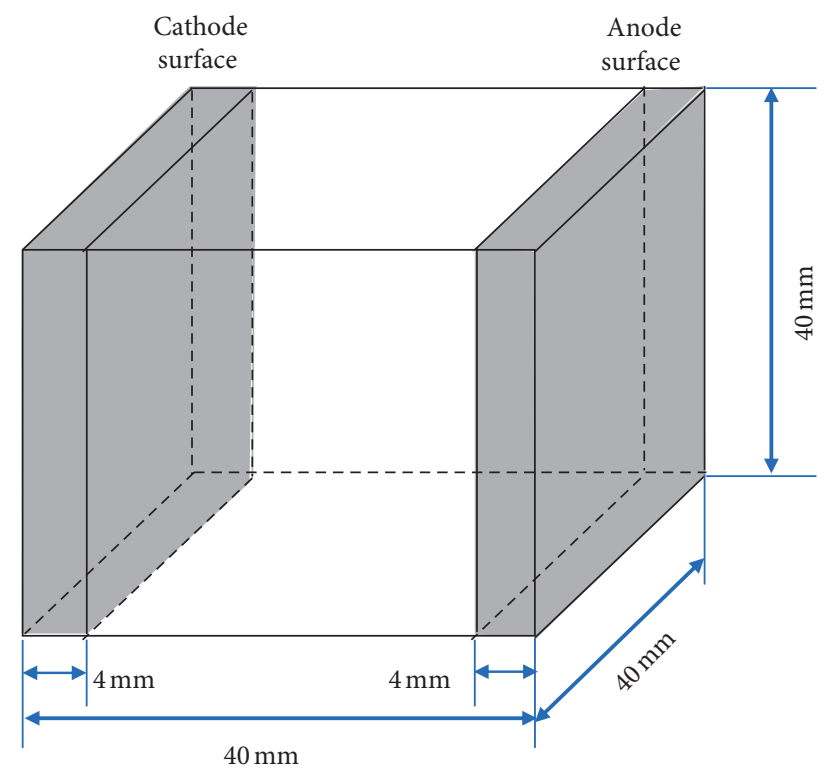

FIgURE 2: Sliced specimen.

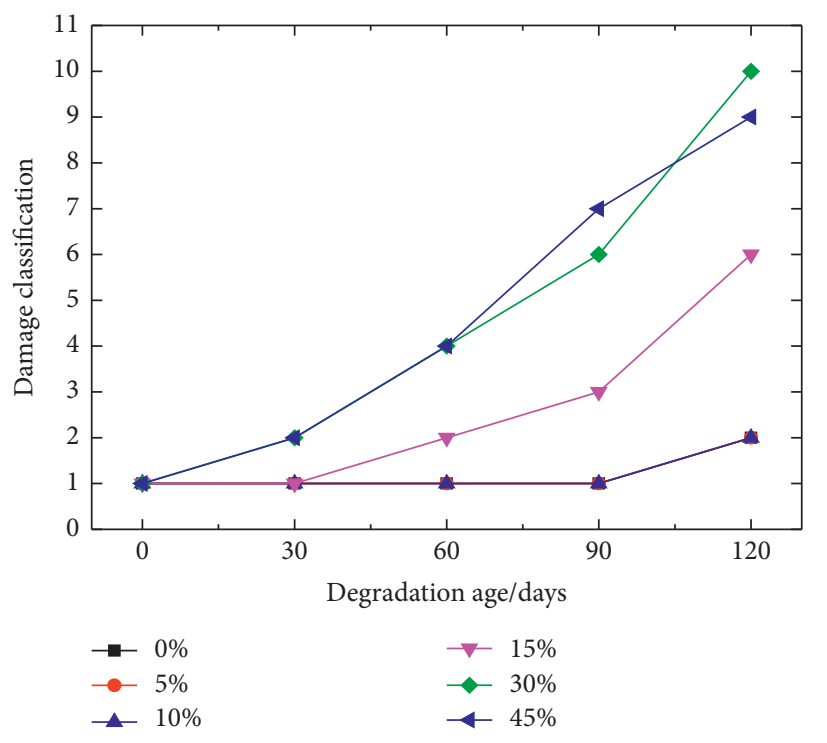

Figure 3: Appearance change grade of different limestone powder contents within 120 days. 


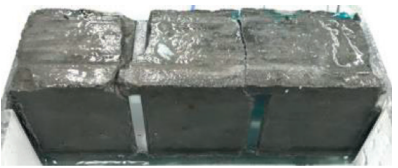

LPC 0\%

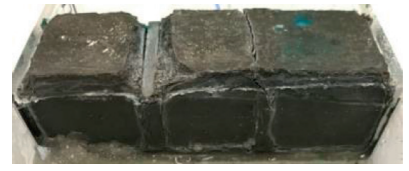

LPC 15\%

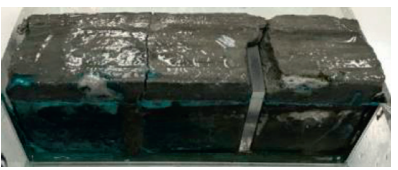

LPC 0\%

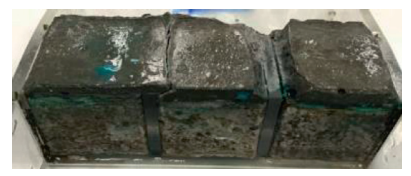

LPC 15\%

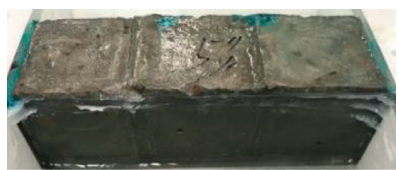

LPC 5\%

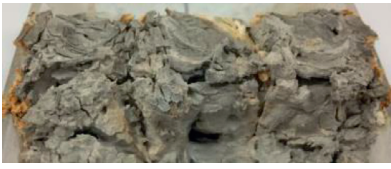

LPC 30\%

(a)

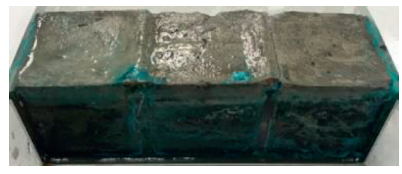

LPC 5\%

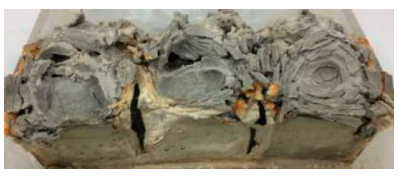

LPC 30\%

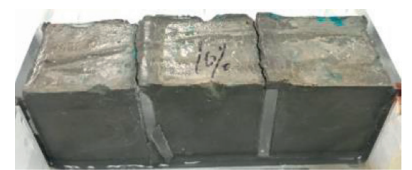

LPC 10\%

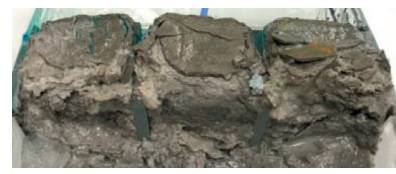

LPC $45 \%$

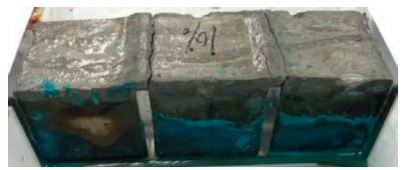

LPC 10\%

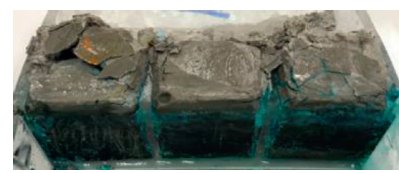

LPC 45\%

(b)

Figure 4: Appearance of different limestone powder contents at 120 days (LPC: limestone powder content). (a) Cathode surface and (b) anode surface.

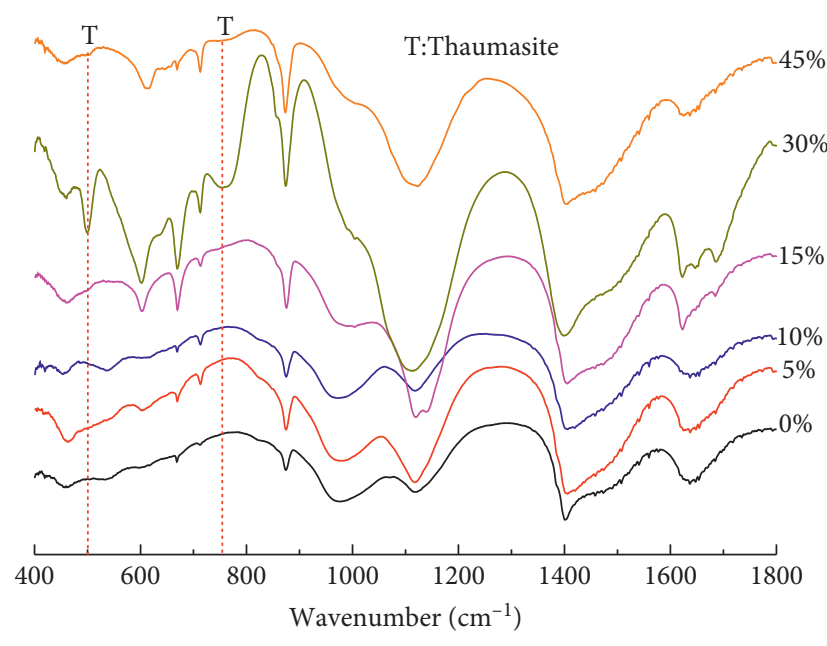

(a)

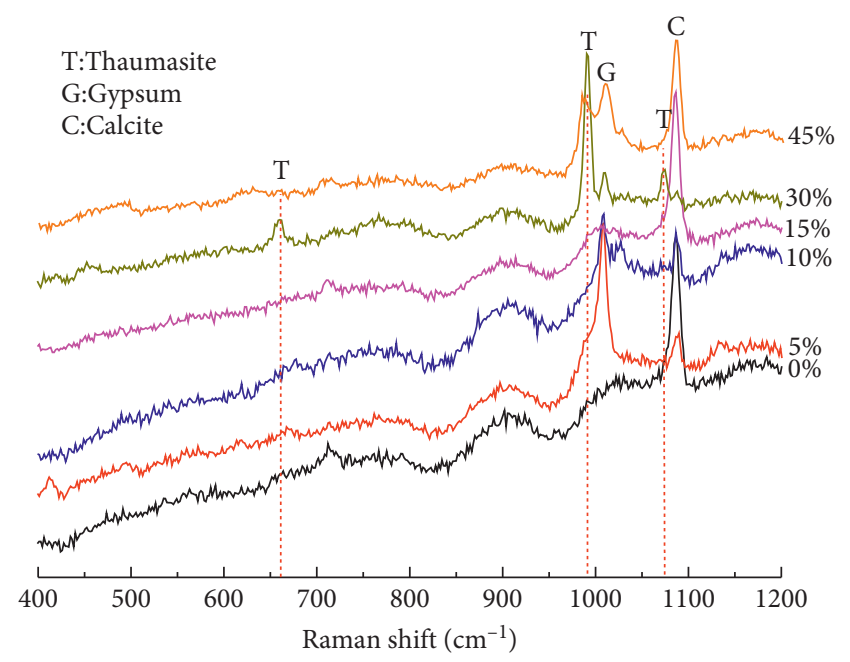

(b)

FIgURE 5: (a) FTIR spectrum and (b) Raman spectrum of the cathode surface for all specimens at 120 days.

limestone powder can stabilize the ettringite because the nucleation effect of limestone powder can stabilize the formation of ettringite. It was difficult to find the presence of gypsum in the positive extreme of the specimen when the dosage of limestone was $5 \%$.

Figure 10 shows the XRD of the cathode surface and the anode surface of specimens with $10 \%$ limestone powder within 120 days. Combined with the above data, according to the FTIR and Raman results, ettringite and gypsum were the main degradation products with $10 \%$ limestone powder, and no thaumasite was found in the specimens. The changes in ettringite and gypsum were not obvious within 120 days, and the changes in calcium hydroxide were also not obvious. After 120 days of electric field action, no serious sulfate attack occurred in the specimen. Limestone powder could promote the formation of ettringite, the limestone powder 
TABle 4: The vibrational spectra and band assignment of thaumasite [21].

\begin{tabular}{lc}
\hline \multicolumn{2}{c}{ Thaumasite } \\
\hline FTIR & Raman \\
1650 & - \\
1400 & - \\
1100 & 1076 \\
940,920 & Characteristic peak: 990 \\
887 & - \\
Characteristic peak: 750 & Characteristic peak: 658 \\
673 & - \\
590 & $479,453,417$ \\
\hline Characteristic peak: 500 &
\end{tabular}

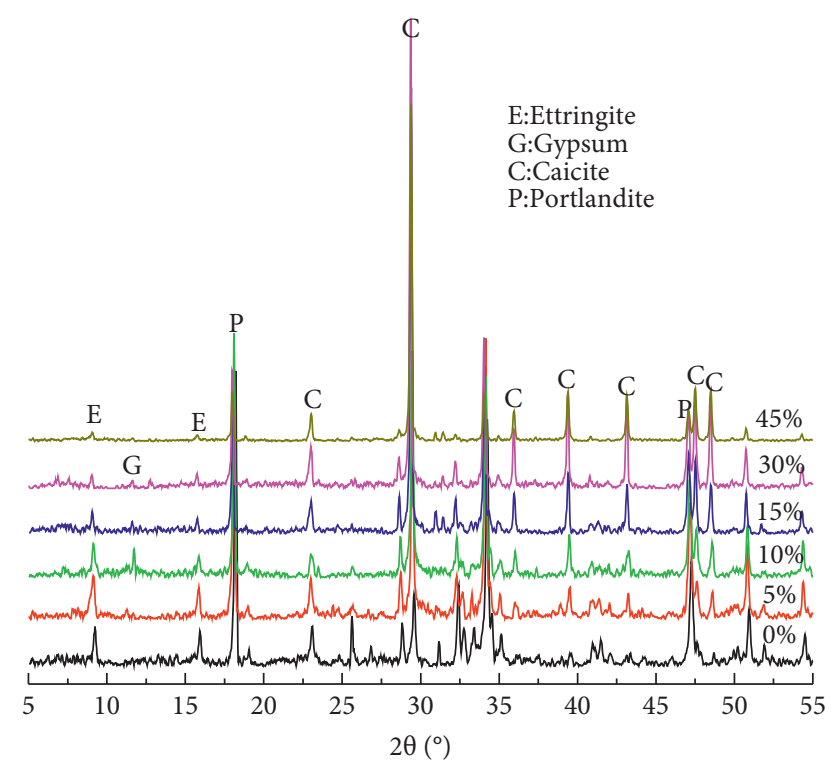

FIgURE 6: XRD pattern of 6 control specimens at 30 days.

content reached $10 \%$, and it could simultaneously promote the formation of ettringite and gypsum.

Figure 11 shows the XRD pattern of the cathode surface and the anode surface of $15 \%$ limestone powder within 120 days. Combined with the above data, according to the FTIR and Raman results, ettringite and gypsum were the main degradation products with $15 \%$ limestone powder, and no thaumasite was found in the specimens. However, as seen from the appearance of the specimen after 120 days of degradation, a small amount of grey pulp was found in the corner cracks of the specimen, indicating that it would be capable of producing thaumasite under a longer degradation period in the future. On the surface of the cathode of the specimen, with the development of the degradation age, the diffraction intensity of the ettringite and gypsum diffraction peaks increased in the specimen, especially between 90 days and 120 days, and the gypsum diffraction peak significantly increased, indicating that a large amount of gypsum was generated on the surface of the cathode of the specimen. In addition, it was observed that the diffraction intensity of the calcium hydroxide diffraction peak on the surface of the cathode decreased gradually with the increase in the degradation age, indicating that the degradation degree occurred deeper in the specimen as time continued. Ettringite and gypsum could still be found on the anode surface of the specimen, but their diffraction intensity was significantly lower than that of calcium hydroxide.

Figure 12 shows the XRD of the cathode surface and the anode surface of $30 \%$ limestone powder within 120 days. Combining the above FTIR and Raman data, there were very serious TSAs in the specimen. The limestone powder content reached $30 \%$, and the specimen anode and the cathode surface had obvious diffraction peaks of thaumasite. Combined with the limestone powder content from $0 \%$ to $15 \%$ in this paper, according to the data on the limestone powder content, the higher the content is, the more accelerated the sulfate attack of the cement base material is; first, ettringite is stabilized, the formation of gypsum speeds second, and finally, the generation of thaumasite is accelerated.

Figure 13 shows the XRD of the cathode surface and the anode surface of $45 \%$ limestone powder within 120 days. Combining the above FTIR and Raman data, little thaumasite was found, and the degradation degree was not urgent for a limestone powder dosage of $30 \%$. The diffraction peaks of ettringite and gypsum were found on the surface of the cathode after 60 days. In addition, the formation of new products, monocarboaluminate and tricarboaluminate, was found. The limestone powder could react with $\mathrm{C}_{3} \mathrm{~A}$ to produce hydrated calcium carboaluminate. The monocarboaluminate was more stable than the other products, and the TSA was slow. The formation of ettringite and hydrated calcium carboaluminate both consumed $\mathrm{C}_{3} \mathrm{~A}$, ettringite and gypsum were hardly found on the cathode surface at 60 days, and little ettringite was found at 90 days, indicating that the formation of hydrated calcium carboaluminate delayed the ettringite and gypsum formation and that the formation of ettringite and gypsum was closely related to thaumasite; thus the generation of thaumasite was delayed. No degradation products were found on the anode surface, and the main products were calcium hydroxide and calcium carbonate.

3.2.3. Chemical Analysis. The changes in the $\mathrm{pH}$ value and the $\mathrm{SO}_{3}$ and $\mathrm{CaO}$ contents on the cathode surface of the 6 groups were tested at 0 days and 120 days. The results are shown in the following figures. The change in the $\mathrm{pH}$ value is shown in Figure 14. The higher the content of limestone powder is, the lower the $\mathrm{pH}$ value of the cathode surface is. The decrease range is small, and the effect is not obvious when the dosage of limestone powder is less than $10 \%$. However, when the content of limestone powder exceeds $15 \%$, the $\mathrm{pH}$ value of the cathode surface begins to drop sharply. For the control group, due to the increase in the content of limestone powder, the cement content is relatively reduced, so the content of the hydration product calcium hydroxide is also reduced; hence, the $\mathrm{pH}$ value in the sample will gradually decrease, but the decrease range is smaller than that for the other groups. The $\mathrm{pH}$ value drops sharply when the dosage of limestone exceeds 15\%, and the higher 


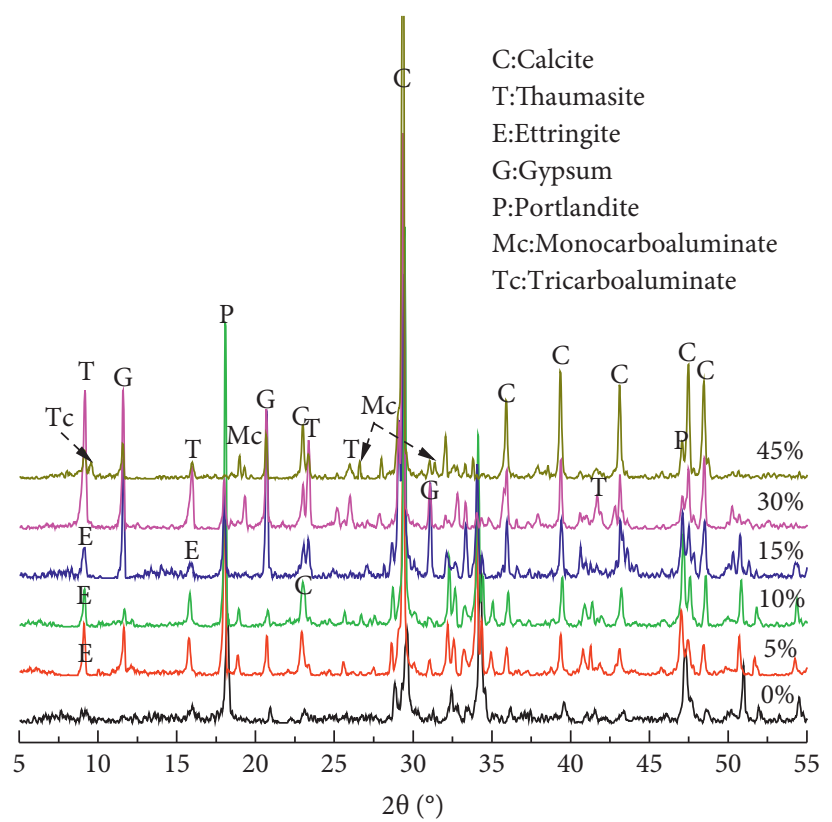

(a)

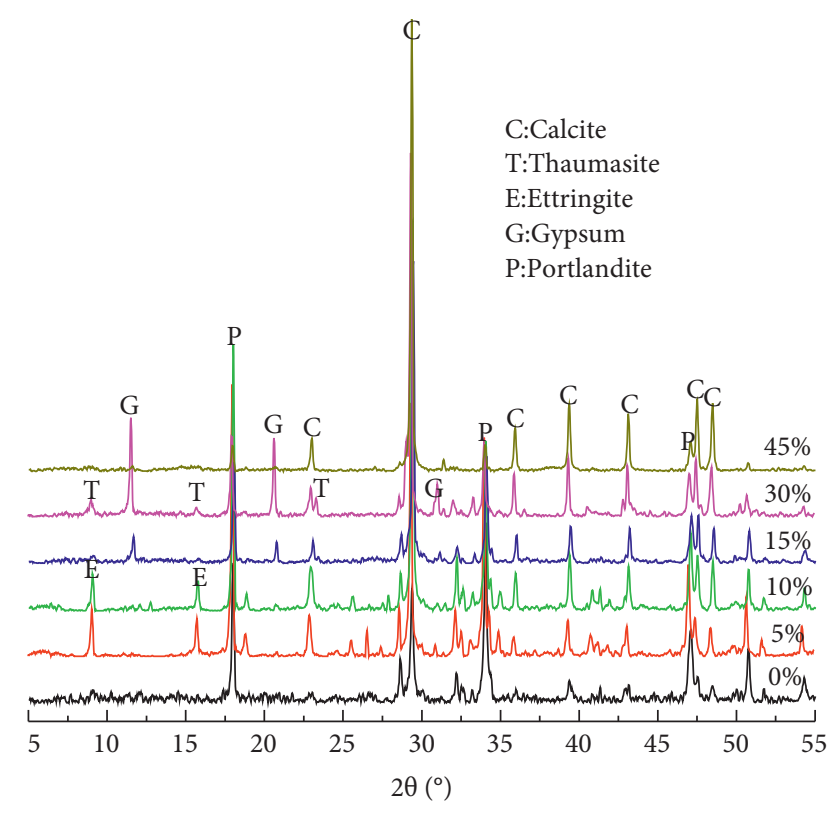

(b)

FIGURE 7: XRD pattern of the cathode surface and anode surface for all specimens at 120 days. (a) Cathode surface and (b) anode surface.

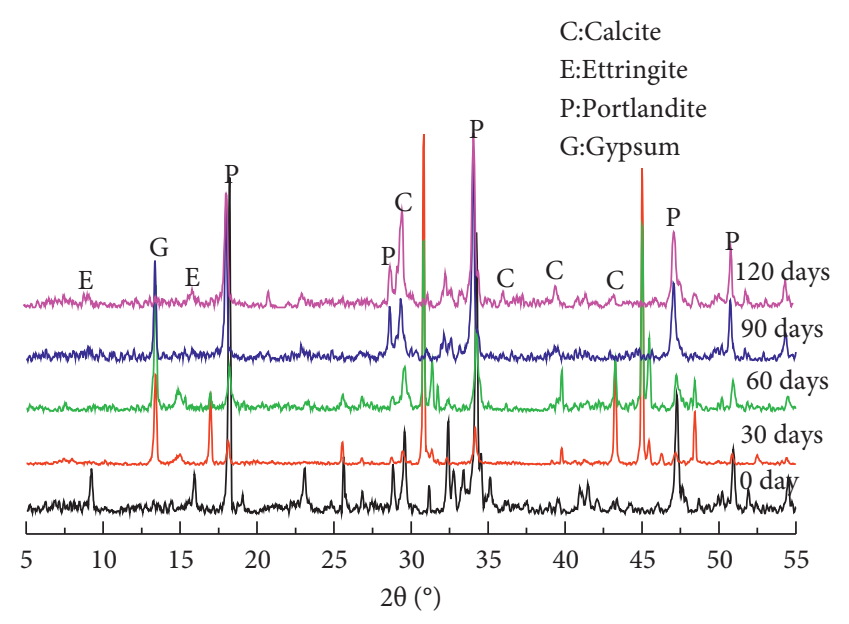

(a)

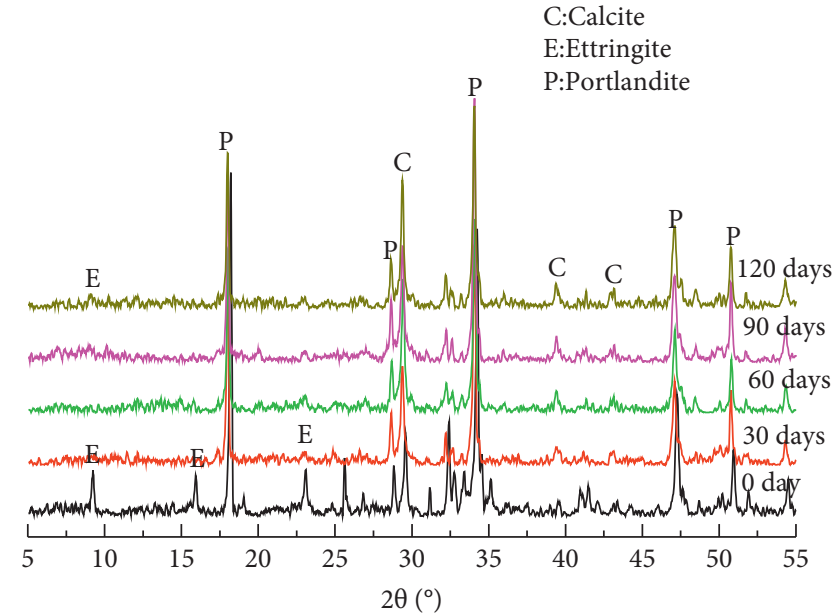

(b)

FIGURE 8: XRD pattern of 0\% limestone powder content within 120 days. (a) Cathode surface and (b) anode surface.

the dosage of limestone, the greater the decline when the specimen is corroded. The more the $\mathrm{pH}$ value decreases, the more the degradation occurs. The $\mathrm{pH}$ value of the cathode surface of the limestone powder group containing $45 \%$ is reduced to approximately 10 at 120 days, and the formation of thaumasite is closely related to the $\mathrm{pH}$ value of the sulfate. In addition, a high concentration of sulfate and high alkalinity can accelerate TSA in concrete $[11,24,25]$. Gaze and Crammond [4] reported that thaumasite is not formed at a $\mathrm{pH}$ of less than 10.5 , and when the $\mathrm{pH}$ is lower than 10.5 , thaumasite is formed into calcite [26]. Hobbs and Taylor believed that a $\mathrm{pH}$ of 12.5 was a necessary condition for the formation of thaumasite [27]. Experiments in [27] have studied the chemical reactions of thaumasite with different solutions: the reactions of thaumasite with phosphate, carbonate, and bicarbonate decrease with increasing $\mathrm{pH}$. When the $\mathrm{pH}$ value is greater than 12.45 , thaumasite is more stable than when the $\mathrm{pH}$ value is less than 12.45 . These studies show that the formation process and TSA cannot occur in an acidic environment, while gypsum is mainly formed in a low $\mathrm{pH}$ environment because gypsum is more stable in a low $\mathrm{pH}$ environment. Therefore, it can be seen from the results of the $\mathrm{pH}$ value of the cathode surface of the specimen that an excessively low $\mathrm{pH}$ value causes the thaumasite to decompose.

The change in the content of $\mathrm{SO}_{3}$ is shown in Figure 15. There was no significant difference in the amount of sulfates transferred into the samples with limestone powder contents 


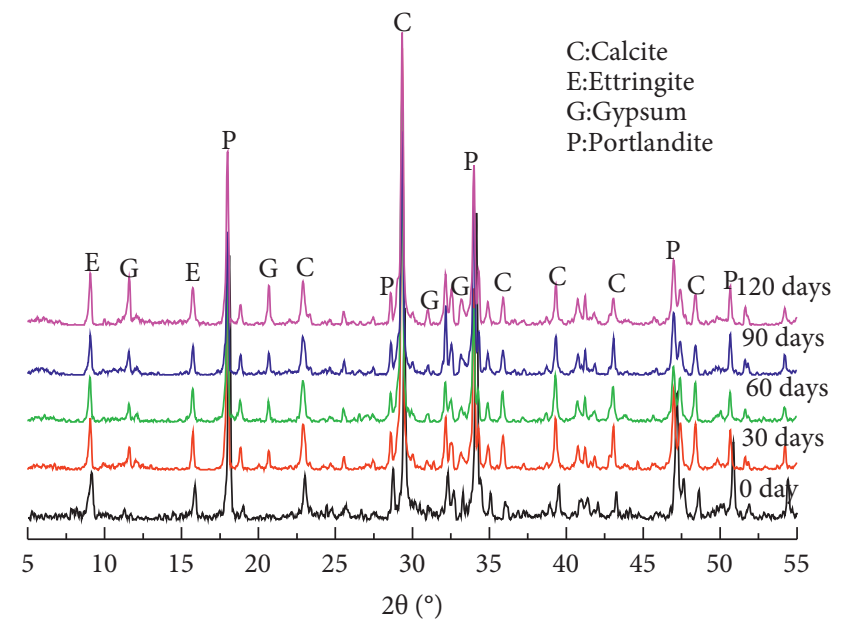

(a)

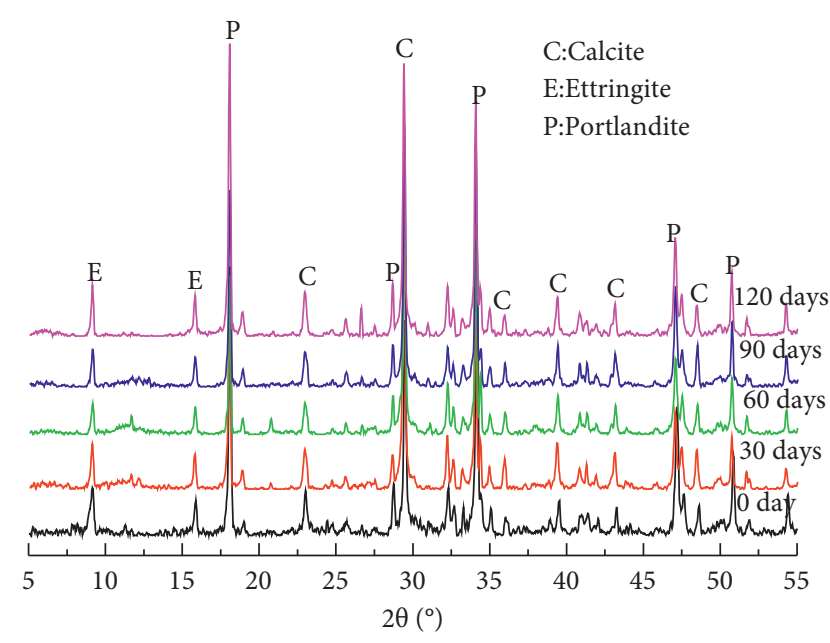

(b)

Figure 9: XRD pattern of 5\% limestone powder content within 120 days. (a) Cathode surface and (b) anode surface.

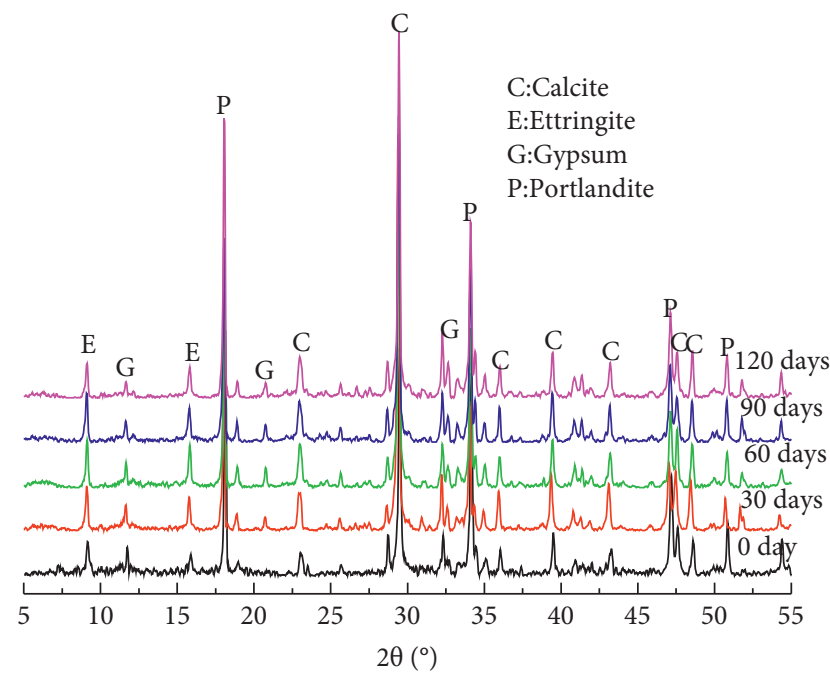

(a)

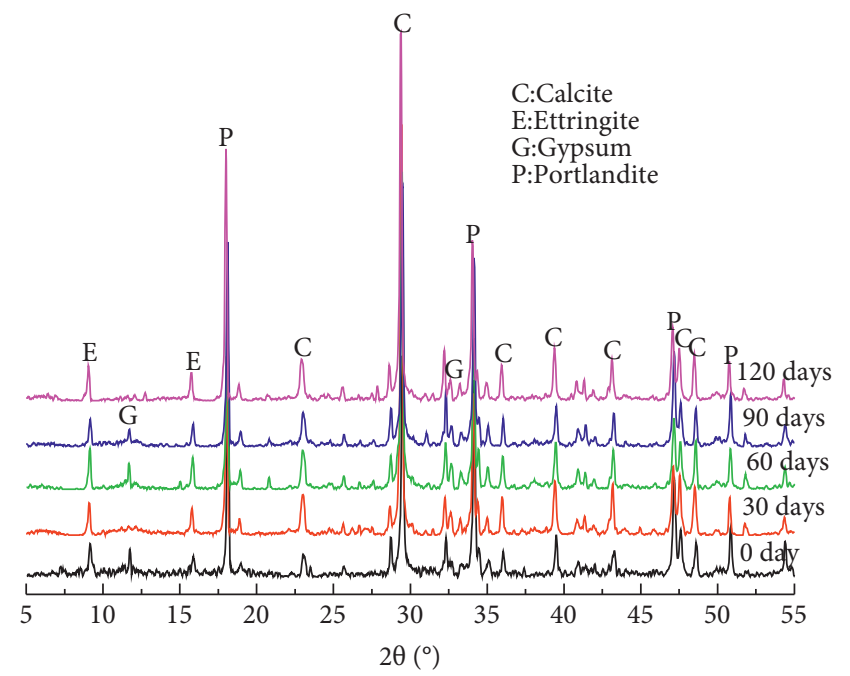

(b)

FIGURE 10: XRD pattern of 10\% limestone powder content within 120 days. (a) Cathode surface and (b) anode surface.

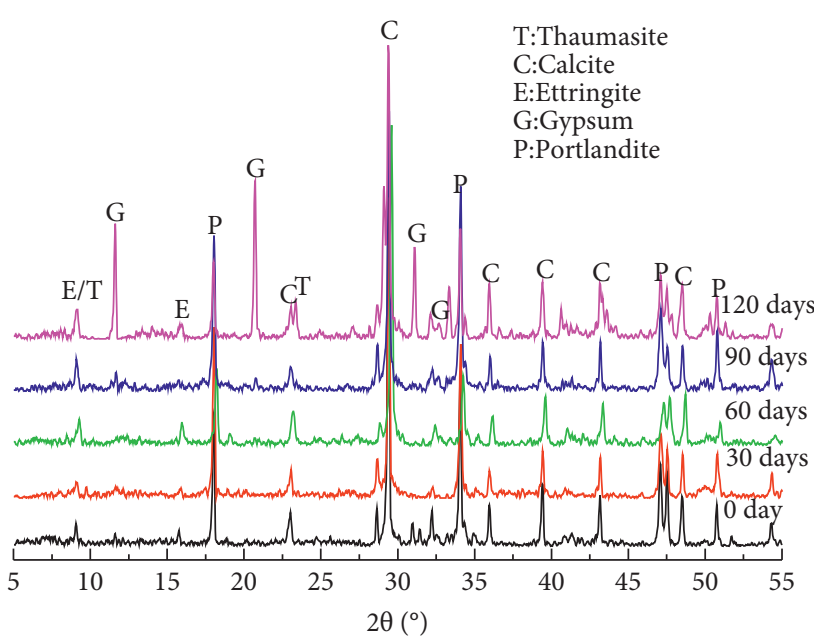

(a)

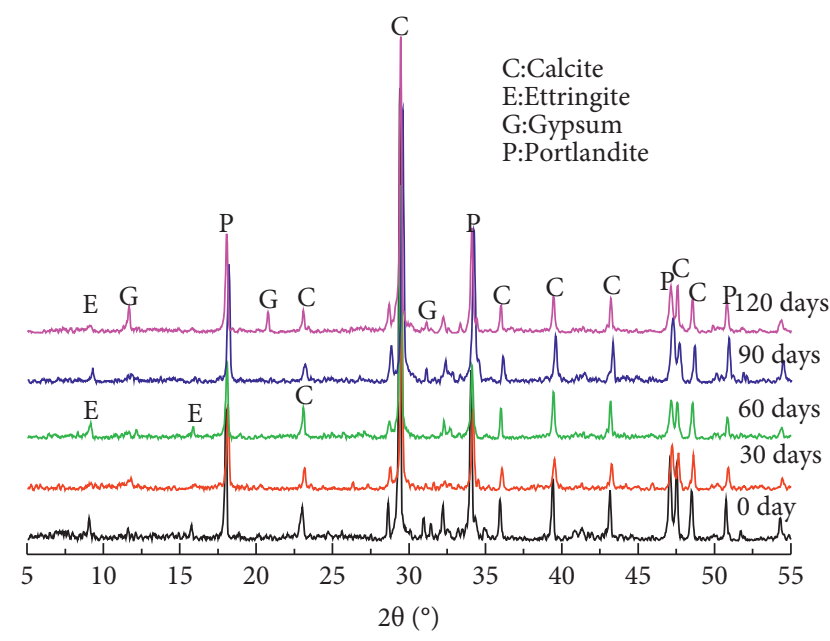

(b)

FIgURE 11: XRD pattern of 15\% limestone powder content within 120 days. (a) Cathode surface and (b) anode surface. 


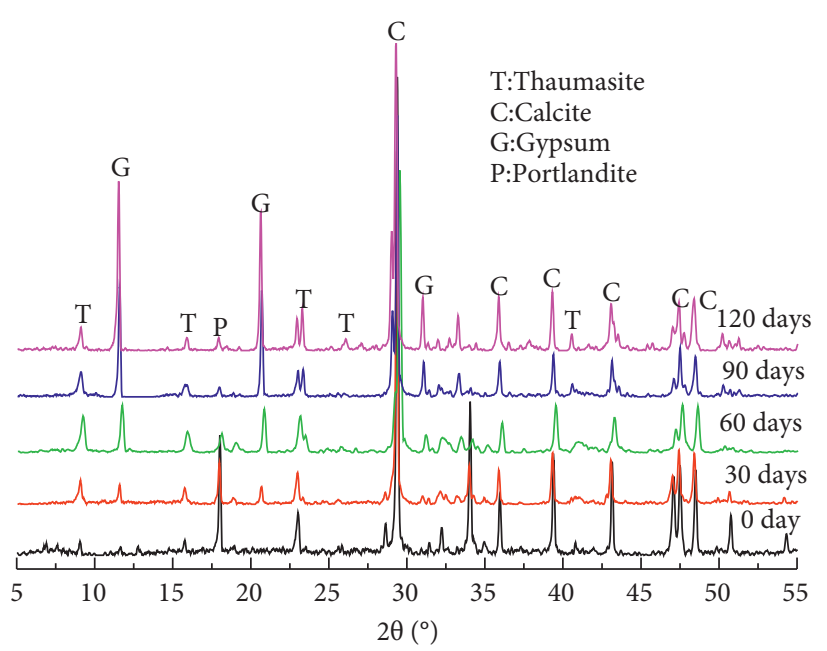

(a)

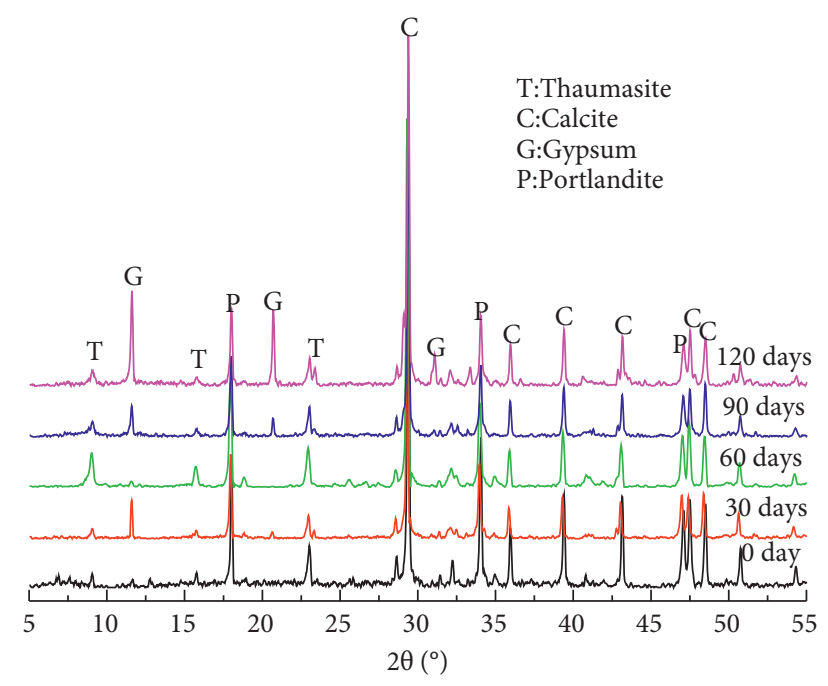

(b)

FIGURE 12: XRD pattern of 30\% limestone powder content within 120 days. (a) Cathode surface and (b) anode surface.

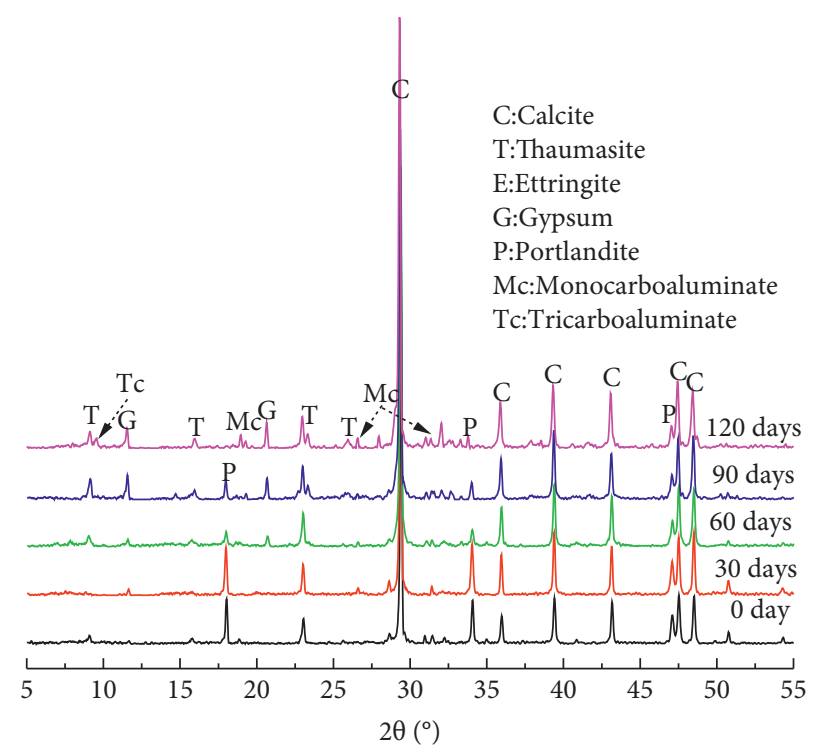

(a)

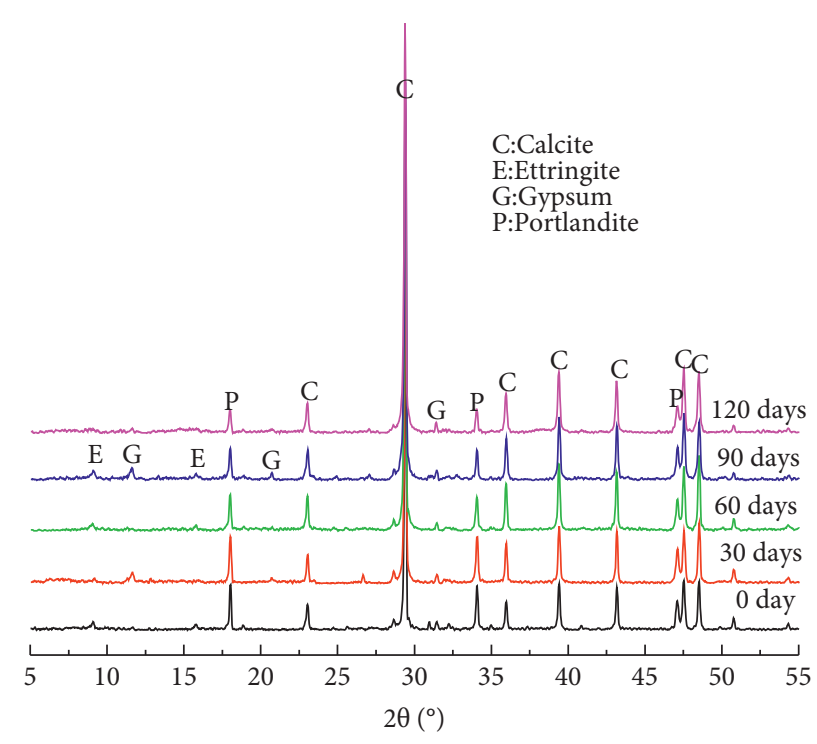

(b)

FIgURE 13: XRD pattern of 45\% limestone powder content within 120 days. (a) Cathode surface and (b) anode surface.

of $0 \%, 5 \%$, and $10 \%$, and the amount transferred into the samples was also very small. However, the content of sulfate migrated into the cement sample increased sharply when the content of limestone powder exceeded $15 \%$, and the higher the content of limestone powder was, the more the sulfate migrated into the sample. The increase in the content of limestone powder correspondingly reduced the content of cement, hydration products, and C-S-H gel, which reduced the compactness of the specimen, facilitating sulfate migration into the specimen. In addition, the nucleation effect of limestone powder participated in generating thaumasite and was advantageous to the cement base material of the sulfate attack, which resulted in cracking of the specimen for further expansion and loosening, resulting in a growing amount of sulfate into the specimen during the reaction; thus, the degradation of the sample was more severe.

The change in the content of $\mathrm{CaO}$ is shown in Figure 16. The $\mathrm{CaO}$ content and the change rule of the specimen were similar with $\mathrm{pH}$ and $\mathrm{SO}_{3}$ content change, the same is within $10 \%$ limestone powder content, the inside of the specimen $\mathrm{CaO}$ content difference is small, and when the limestone powder content exceeds $15 \%$, the decalcification of the cathode region becomes more pronounced, especially when limestone powder content is $45 \%$.

The addition of limestone powder can promote the sulfate attack of cement-based materials due to the stabilization of the ettringite; it can also promote a very large formation of gypsum. The limestone powder content is $5 \%$ 


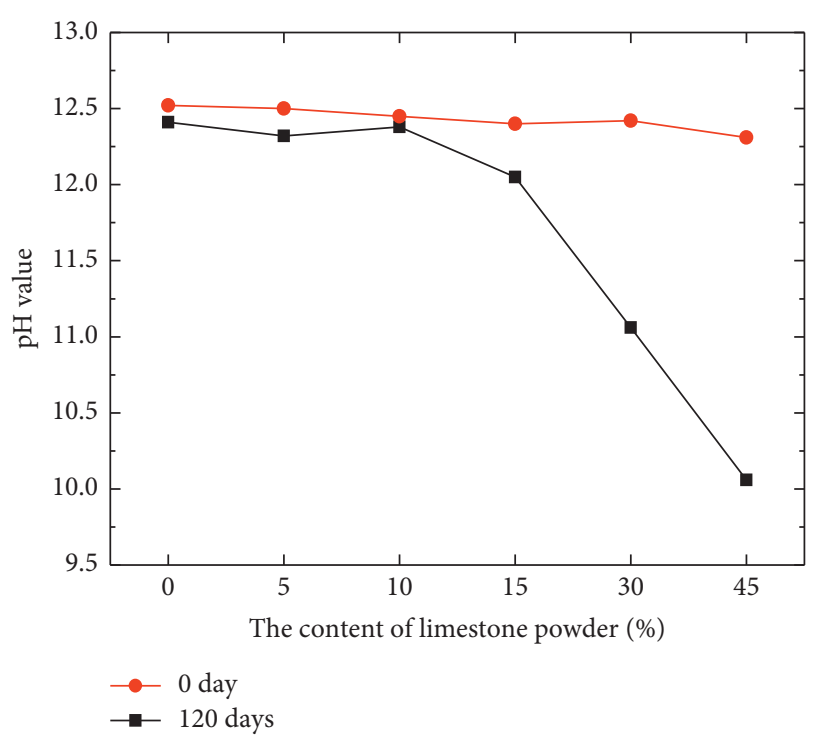

FIGURE 14: $\mathrm{pH}$ of the cathode surface for all the samples at 120 days.

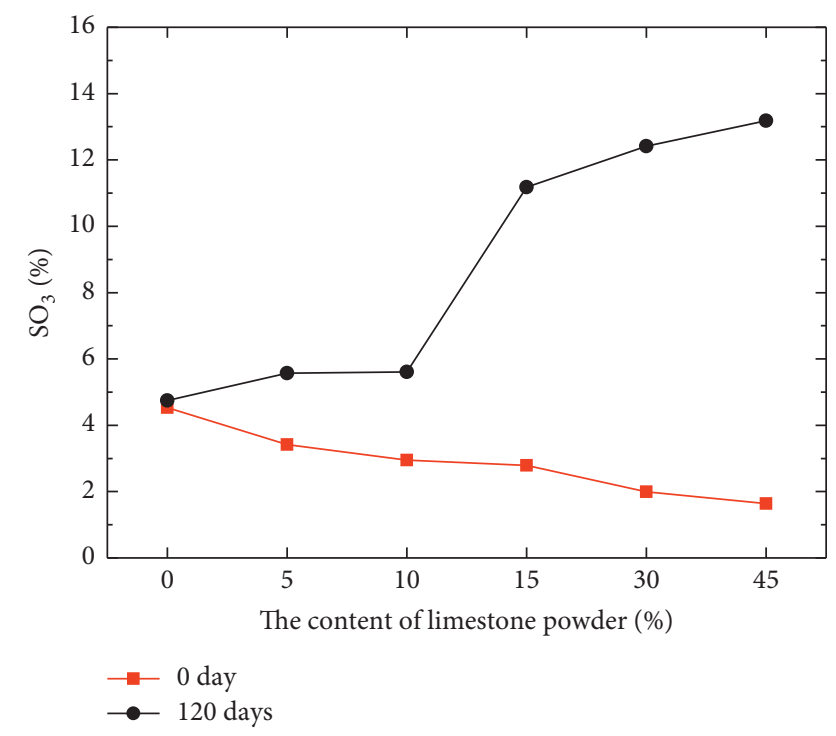

FIGURE 15: $\mathrm{SO}_{3}$ content of the cathode surface for all the samples at 120 days.

and $10 \%$, compared with the $0 \%$ limestone powder content. The above XRD data show that the specimen generated a large amount of ettringite and gypsum. Combined with the above data, the limestone powder content is within $10 \%$, and the $\mathrm{pH}$ change and $\mathrm{SO}_{3}$ content of the cathode surface show little change. The dosages of $5 \%$ and $10 \%$ limestone powder do not accelerate more sulfate into the specimen, and the specimens still generate a large amount of gypsum and ettringite, indicating that the limestone powder has a promoting effect on sulfate attack. The sulfate attack of cementbased materials by limestone powder begins to change qualitatively when the content of limestone exceeds $10 \%$. The chemical reaction is accelerated, and the replacement of limestone powder reduces the density and stability of the cement-based materials, which is mainly manifested in

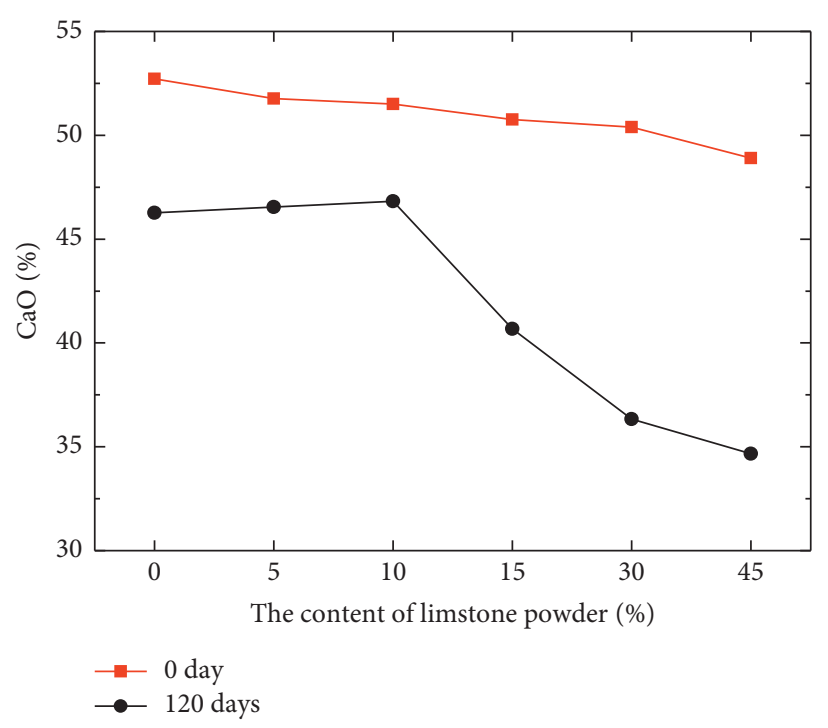

Figure 16: $\mathrm{CaO}$ content of the cathode surface in all samples at 120 days.

reducing the $\mathrm{pH}$ value of cement-based materials, speeding up the process of sulfate attack and experiencing severe TSA. The $\mathrm{pH}$ of cement-based materials is too low when the content of limestone powder is $45 \%$, which leads to the degradation products being decomposed (except the gypsum). In addition, more limestone powder also reacts with $\mathrm{C}_{3} \mathrm{~A}$ to generate hydrated calcium carboaluminate, which can delay the TSA.

\section{Conclusions}

This paper studies the effects of different contents of limestone powder on the TSA in cement-based materials for studying the influence degree and mechanism of limestone powder content on TSA; the limestone powder contents are $0 \%, 5 \%, 10 \%, 15 \%, 30 \%$, and $45 \%$. The degradation process and mechanism were analyzed by appearance, FTIR, Raman, XRD analysis, and chemical analysis.

It can be clearly found that although limestone powder can lead to serious TSA of cement-based materials, the degree of corrosion is closely related to the content of limestone powder, and the degree of corrosion is not completely linear with the content of limestone powder. The effect of limestone powder on the sulfate attack of cementbased materials is low, and it will not cause obvious sulfate attack when the content of limestone powder is no more than $10 \%$. Limestone powder can cause severe TSA when the content of limestone powder is $15 \%-30 \%$. TSA actually decreased when the content of limestone powder is $45 \%$ because the more limestone powder also reacts with $\mathrm{C}_{3} \mathrm{~A}$ to generate hydrated calcium carboaluminate, which can delay the TSA. The details results are discussed as follows:

(1) There was no obvious sulfate attack when the content of limestone powder was not more than $10 \%$. However, the $5 \%$ content of limestone powder can stabilize the ettringite, and the $10 \%$ content of 
limestone powder can promote the formation of gypsum.

(2) The sulfate attack was obviously accelerated when the content of limestone powder was more than $15 \%$, especially when the TSA was obviously accelerated when the content of limestone powder was $30 \%$.

(3) There were new products in which monocarboaluminate and tricarboaluminate were found when the content of limestone powder was $45 \%$, and the degradation of TSA was also delayed when compared with a limestone powder content of $30 \%$.

(4) The limestone powder can lead to a rapid decrease in the $\mathrm{pH}$ and the content of $\mathrm{CaO}$ and a rapid increase in the content of $\mathrm{SO}_{3}$ when the content of limestone powder is more than $10 \%$, which accelerates the sulfate attack. The excessive limestone powder content, in which the content of limestone powder is $45 \%$, leads to the $\mathrm{pH}$ being excessively low and is a disadvantage for the degradation products.

\section{Data Availability}

The data used to support the findings of this study are included within the article.

\section{Conflicts of Interest}

There are no conflicts of interest.

\section{Acknowledgments}

The authors want to acknowledge the financial support of the China West Construction Group Co., Ltd., Science and Technology Research and Development Foundation (nos. ZJXJ-2019-12 and ZJXJ-2019-13) and the National Natural Science Foundation of China (no. 51772033).

\section{References}

[1] M. Collepardi, "Thaumasite formation and deterioration in historic buildings," Cement and Concrete Composites, vol. 21, no. 2, pp. 147-154, 1999.

[2] G. Britain, The Thaumasite Sulfate Attack Risks, Diagnosis, Remedial Works and Guidance on New Construction, DETR: Report of the Thaumasite Expert Group, London, UK, 1999.

[3] T. Schmidt, Sulfate Attack and the Role of Internal Carbonate on the Formation of Thaumasite, EPFL, Lausanne, Switzerland, 2007.

[4] M. E. Gaze and N. J. Crammond, "The formation of thaumasite in a cement:lime:sand mortar exposed to cold magnesium and potassium sulfate solutions," Cement and Concrete Composites, vol. 22, no. 3, pp. 209-222, 2000.

[5] H. F. W. Taylor, Cement Chemistry, Inst of Civil Engineers Pub, London, UK, 2nd edition, 1997.

[6] T. Schmidt, B. Lothenbach, M. Romer, K. Scrivener, D. Rentsch, and R. Figi, "A thermodynamic and experimental study of the conditions of thaumasite formation," Cement and Concrete Research, vol. 38, no. 3, pp. 337-349, 2008.

[7] S. J. Barnett, D. E. Macphee, E. E. Lachowski, and N. J. Crammond, "XRD, EDX and IR analysis of solid solutions between thaumasite and ettringite," Cement and Concrete Research, vol. 32, no. 5, pp. 719-730, 2002.

[8] M. A. González and E. F. Irassar, "Effect of limestone filler on the sulfate resistance of low C3A Portland cement," Cement and Concrete Research, vol. 28, no. 11, pp. 1655-1667, 1998.

[9] E. F. Irassar, V. L. Bonavetti, and M. González, "Microstructural study of sulfate attack on ordinary and limestone Portland cements at ambient temperature," Cement and Concrete Research, vol. 33, no. 1, pp. 31-41, 2003.

[10] I. R. Holton, N. J. Crammond, and W. F. Price, Comparative Performance of portland limestone Cement Concretes and Portland Cement Concretes in Cold Calcium Sulfate Solutions. (Personal Communication of Unpublished Draft Paper), 2007.

[11] M. Pauri and M. Collepardi, "Thermo-hygrometrical stability of thaumasite and ettringite," Il Cemento, vol. 86, pp. 177-184, 1989.

[12] T. T. Knudsen, "Its stability and formation. A literature review and report, eureka project EU-672," Eurocare-Thaumasite, pp. 1-21, 1990.

[13] I. Juel, J. Konnerup-Madsen, D. Herfort, R. Gollop, H. J. Jakobsen, and J. Skibsted, "A thermodynamic model for predicting the stability of thaumasite," Cement and Concrete Composites, vol. 25, no. 8, pp. 867-872, 2003.

[14] R. D. Hooton and M. D. A. Thomas, The Use of Limestone in Portland Cements: Effect on Thaumasite Form of Sulfate Attack, Portland Cement Association, Skokie, IL, USA, 2002.

[15] N. S. Soroka, "Effect of calcareous fillers on sulfate resistance of Portland Cement," American Ceramic Society Bulletin, vol. 55, no. 6, pp. 594-595, 1976.

[16] N. S. Soroka, "Effect of mineral fillers on sulfate resistance of Portland cement mortars," in Durability of Building Materials and Components, P. J. Sereda and G. G. Litvan, Eds., pp. 326-335, ASTM, West Conshohocken, PA, USA, 1980.

[17] N. Crammond, "The occurrence of thaumasite in modern construction-a review," Cement and Concrete Composites, vol. 24, no. 3-4, pp. 393-402, 2002.

[18] Spring, EN 197-1-2011, Cement. Composition, Specifications and Conformity Criteria for Common Cements, Spring, Singapore, 2011.

[19] Y. Luo, C. Wang, C. Luo, Q. Huang, S. Wang, and X. Peng, "Effect of electrical field on TSA failure of cement-based materials," Cement and Concrete Research, vol. 90, pp. 19-26, 2016.

[20] Y. Luo, C. Wang, Z. Fang, L. Xiao, and Q. Zeng, “The TSA degradation process of cement-based materials in the electrical field environment," Construction and Building Materials, vol. 206, pp. 703-716, 2019.

[21] Y. Luo, C. Wang, F. Zheng et al., "The sulfate degradation of cement incorporating carbonate by an electrical field at low temperature," Advances in Cement Research, vol. 32, no. 9, pp. 398-412, 2020.

[22] Q. Zeng, C. Wang, Y. Luo, C. Yu, Q. Huang, and C. Luo, "Effect of temperatures on TSA in cement mortars under electrical field," Construction and Building Materials, vol. 162, pp. 88-95, 2018.

[23] 2017 GB/T 176-2017, Methods for chemical analysis of cement.

[24] P. C. Hewlett, Lea's Chemistry of Cement and Concrete, Arnold, Boston, MA, USA, 1998.

[25] J. R. Clifton, G. Frohnsdorff, and C. Ferraris, "Standards for evaluating the susceptibility of cement-based materials to external sulfate attack," in Material Science of Concrete-Sulfate Attack Mechanisms, J. Skalny and J. Marchand, 
Eds., pp. 337-355, American Ceramic Society, Westerville, OH, USA, 1999.

[26] L. A. Clark, Thaumasite Expert Group Report: Review after Three Years of Experience, p. 41, Office of the Deputy Prime Minister, London, UK, 2002.

[27] E. F. Irasser, V. L. Bonavetti, M. A. Trezza, and M. A. González, "Thaumasite formation in limestone filler cements exposed to sodium sulfate solution at $20^{\circ} \mathrm{C}$," Cement and Concrete Composites, vol. 27, pp. 77-84, 2005. 